\title{
As fronteiras entre a ficção e a realidade em Vivir para contarla de Gabriel García Márquez
}

\author{
José Veranildo Lopes da Costa Junior ${ }^{1}$ \\ Ariadne Costa da Mata ${ }^{2}$
}

\begin{abstract}
Resumo: Muitos nomes têm sido dados, ao longo do tempo, à literatura produzida em primeira pessoa, cujo objetivo principal é contar a vida do próprio autor: escritas de si, literatura do "eu", literatura memorialística, autobiografia ou autoficção. Na literatura latino-americana, as escritas de si estão presentes há séculos, empregadas por diversos escritores que se aventuraram a narrar suas histórias no descobrimento da América, no exílio, na ditadura e em outros momentos históricos do continente. No século XXI, Gabriel García Márquez ingressa nessa linhagem com sua autobiografia Vivir para contarla (2007), que representa um marco para entender a história do realismo mágico e conhecer as memórias do escritor. Neste artigo, nos propomos a analisar a autobiografia do escritor colombiano refletindo sobre as características do gênero, sobretudo com relação às tênues fronteiras da ficção e da realidade. Para tanto, nos fundamentamos nas contribuições teóricas de Gasparini (2014), Klinger (2007), Lejeune (2008), Noronha (2014), entre outros.
\end{abstract}

Palavras-chave: Escritas de si. Gabriel García Márquez. Autobiografia.

\section{The borders between fiction and reality in Gabriel Gárcia Márquez}

\begin{abstract}
Many names have been given, over time, the literature produced in first person, which the main purpose is to talk about the author: memory, autobiography, autofiction, writing of the self and others. In Latin American literature, these writings of the self have been used for centuries: it can be seen, for instance, in the writings of the European travelers, in the exile writings and in the post-dictatorship testimonials. In the 21st Century, Gabriel García Márquez leaves his contributions to that archive by publishing his autobiography Vivir para contarla (2007), which soon becomes a landmark, offering a personal account of the history of magical realism. In this paper, we provide a brief analysis of that text and discuss some of the problems involving the concept of autobiography, mainly the confusing relations between fiction and reality.
\end{abstract}

Keywords: Writings of the self. Gabriel García Márquez. Autobiography.

\section{1- Introdução}

\footnotetext{
${ }^{1}$ Possui graduação em Letras - Língua Espanhola pela Universidade Estadual da Paraíba - UEPB. É mestrando em Linguagem e Ensino pela Universidade Federal de Campina Grande - UFCG. Contato: jveranildo@hotmail.com

2 Doutora em Literatura pela Pontifícia Universidade Católica do Rio de Janeiro - PUC. Professora de Literatura Hispânica no Departamento de Letras e Artes da Universidade Estadual da Paraíba - UEPB. Contato: ariadnecosta@gmail.com
} 
Nos últimos anos, escritores e figuras públicas brasileiras se envolveram em uma polêmica relacionada à publicação de biografias não autorizadas no mercado editorial brasileiro. Para além das paixões que alimentam o debate, o sucesso dessas obras parece sinalizar um movimento na sociedade de interesse e curiosidade pela vida do outro e da transformação da intimidade em objeto de consumo. Vivemos, por assim dizer, uma cultura de exposição da intimidade e de ânsia pelo real, de busca de uma experiência da realidade do outro (aparentemente) sem mediação, que se pode perceber nos mais diversos espaços midiáticos, como as redes sociais, o Facebook e o Instagram, além dos realities show.

Quando tratamos da exposição do "eu" na literatura, entretanto, é preciso recordar que esta é uma tendência firmada e consolidada, com uma história antiquíssima. ${ }^{2}$ Neste sentido, percebe-se que falar sobre si, ainda que seja uma prática recorrente na contemporaneidade, é uma prática estabelecida há muito tempo.

Neste trabalho, interessa-nos, especificamente, a incursão de Gabriel García Márquez na escrita de si. Ainda que à margem da produção literária do escritor colombiano, Vivir para contarla, cuja primeira edição foi lançada em 2002 na cidade de Buenos Aires, representa um marco na escrita autobiográfica latino-americana, pois além de ser considerado um dos mais completos registros sobre a vida do colombiano, constitui uma peça importante na historiografia literária do continente, ao oferecer um relato pessoal do realismo mágico. ${ }^{3}$

O que nos interessa discutir particularmente, aqui, é a tensão entre a realidade a ficção na autobiografia de García Márquez. Partimos da memória como instrumento chave na narrativa em questão, para mostrar como o próprio autor problematiza o conceito de autobiografia como um gênero pertencente à realidade e coloca em questão a noção de pacto autobiográfico, formulada por Philippe Lejeune, que tem sido tão central para os estudos da autobiografia.

\footnotetext{
2 Lembramos que Foucault, por exemplo, localiza as práticas das escritas de si nos filósofos pré-socráticos (2009), mostrando o quão antiga é esta forma de escrever para o Ocidente. O âmbito latino-americano é permeado de histórias pessoais narradas em diversos gêneros, como memórias, crônicas, cartas, discursos políticos e autobiografias. E embora um paradigma de leitura baseado na noção de autonomia tenha mantido boa parte das escritas de si em uma posição periférica nos estudos literários, hoje elas ocupam um dos eixos principais da crítica literária no continente.

3 Acreditamos que Gabriel García Márquez corrobora com uma espécie de relato pessoal sobre a criação do realismo mágico colombiano a partir da escrita de sua autobiografia, pois é perceptível que em muitos momentos da narrativa a história do escritor se confunde com a história de um novo estilo literário baseado no maravilhoso e no fantástico em vigor na Colômbia.
} 


\section{2- As escritas de si na América Latina}

Falar de si, na cultura Ocidental, é uma prática estabelecida e firmada desde muito tempo, provavelmente inaugurada com as Confissões de Agostinho. Contudo, percebe-se que, na contemporaneidade, novas práticas para falar na primeira pessoa surgiram com o advento da Internet. Assim, com as novas formas midiáticas de comunicação - como as redes sociais - vivemos um período de exposição frenética do "eu" e da intimidade espetacularizada, que parece substituir as antigas formas confessionais, como observa Diana Klinger:

O avanço da cultura midiática de fim de século oferece um cenário privilegiado para a afirmação desta tendência. Nela se produz uma crescente visibilidade do privado, uma espetacularização da intimidade e a exploração da lógica da celebridade, que se manifesta numa ênfase tal do autobiográfico, que é possível afirmar que a televisão se tornou um substituto secular do confessionário eclesiástico e uma versão exibicionista do confessionário psicanalítico. (KLINGER, 2007, p. 22)

Assim, a espetacularização do "eu" é uma marca da contemporaneidade. Este século inaugura um consumo frenético de venda do "eu", através da mídia - no talk show, reality show, ou com o surgimento de novos espaços de exposição, como blogs e relatos de viagem, memórias, testemunhos, romances, filmes, vídeos, retratos, álbuns de fotos, perfis pessoais no Facebook e no Instagram e entrevistas, por alguns exemplos contundentes. Neste contexto, surge um renovado interesse nas obras memorialistas.

Efetivamente, cada vez interessa mais a (típica) biografia de notáveis e famosos ou sua "vivência" captada no instante; há um indubitável retorno do autor, que inclui não somente a ânsia de detalhes de sua vida, mas os

"bastidores" de sua criação; multiplicam-se as entrevistas "qualitativas" que vão atrás da palavra do ator social; persegue-se a confissão antropológica ou o testemunho do "informante-chave". Mas não apenas isso: assistimos a exercícios de "ego-história", a um auge de autobiografias intelectuais, à narração autorreferente da experiência retórica e à autobiografia como matéria da própria pesquisa, sem contar a paixão pelos diários íntimos de filósofos, poetas, cientistas e intelectuais. E, é preciso dizê-lo, às vezes não há muita diferença de tom entre esses exercícios de intimidade e a intrusão nas vidas célebres ou comuns com as quais nos depara diariamente a televisão. (ARFUCH, 2010 p. 61)

No contexto da América Latina, as escritas de si representam uma forte tendência literária marcada por inúmeros eventos que correspondem à ânsia de escrever memórias, 
de relatar o ocorrido sob uma perspectiva pessoal. Este continente, durante muito tempo, sofreu com a ditadura, o exílio e a repressão política, eventos que contribuíram com a proliferação de narrativas cujo objetivo era contar as histórias vividas pelos próprios narradores. De acordo com Diana Klinger, a escrita de si "é uma das tradições mais antigas do Ocidente, [...] profundamente enraizada quando Agostinho começa a escrever as Confissões, que geralmente são citadas como primeiro referente de uma escrita autobiográfica" (KLINGER, 2007, p. 27).

Todorov (2011) comenta que a América Latina foi palco do encontro mais assombroso já visto entre dois homens. $\mathrm{O}$ autor analisa a conquista da América a partir dos conceitos de identidade e alteridade, considerando para tanto, o encontro entre os índios e o Europeu. É clara a presença das escritas de si neste contexto, evidenciada através das cartas de Colombo e dos relatos de viajantes sobre as Índias, mas também em diversos testemunhos indígenas da conquista, como os reunidos no Códice Florentino, por Bernardino de Sahagún.

As escritas de si são caracterizadas pela presença marcante da primeira pessoa no discurso, cujo tema central é contar a história da vida do próprio narrador. As ditaduras militares, entre as décadas 1960 e 1980, geraram numerosos relatos em primeira pessoa, narrando as atrocidades cometidas nas terras latino-americanas: "Nesse contexto, aparecem inúmeros relatos memorialísticos das experiências dos jovens políticos ou dos exilados [...] que podem ser considerados como testemunho de uma geração"

(SANTIAGO (1988) apud KLINGER (2007, p 24)).

De fato, na Argentina do século XIX, a literatura autobiográfica, que remete a figuras públicas relevantes no processo de construção da nacionalidade, é inseparável da construção dessa identidade. A importância da escrita autobiográfica é tal que Noé Jitrik chega afirmar que "o que chamamos de literatura argentina para o século XIX são memórias, como as do General Paz, autobiografias, como as de Sarmiento, ou diários, como os de Mansilla, por dar alguns exemplos contundentes". (KLINGER, 2007, p. 23).

Desta forma, percebe-se a importância da escrita autobiográfica para a América Latina e, em especial, para a Argentina, cuja produção literária é marcada pela primeira pessoa. Ainda neste contexto de ditadura, sobretudo no Cone Sul, entre países que viveram ditaduras sangrentas, as práticas de leitura e as práticas culturais de grande parte 
da população é influenciada pelo cultivo da memória e pela tentativa de preservar os fatos históricos em uma luta constante contra o esquecimento. 4

\section{3- Autobiografia e autoficção como subgêneros das escritas de si}

Paul Ricoeur defende que "o conhecimento de si pressupõe a forma narrativa" e que narrar, colocando "em forma de narrativa de maneira concordante os acontecimentos heterogêneos da existência", é uma estratégia fundamental na constituição da subjetividade (RICOEUR apud COMPAGNON, 2009, p.33 e 49). Podemos entender as escritas de si, portanto, como uma resposta a uma necessidade fundamental do indivíduo. No entanto, essa narrativa de si tenta dar conta não só de eventos concretos, mas da percepção que o indivíduo narrador tem desses eventos, uma percepção que é afetada pelo lugar de fala, pelos afetos, pela distância que existe entre o evento e o momento da narração, pela falibilidade da memória como instrumento, às vezes único, de recuperação dos fatos passados. Assim, é difícil sustentar uma relação de transparência perfeita entre a narrativa, mesmo a mais pessoal, e seu referencial - os eventos reais e mesmo as sensações das quais tenta dar conta. É precisamente esta relação complicada entre a narrativa e seu referente o que dificulta a definição da autobiografia.

Na perspectiva de Philippe Lejeune (2007), a autobiografia estaria caracterizada pela presença de quatro elementos: a) forma da linguagem: narrativa em prosa; $b$ ) o assunto tratado: vida individual, história de uma personalidade; c) a situação do autor: identidade entre autor e narrador e d) a posição do narrador: localizado no presente, ele adota uma visão retrospectiva dos eventos. Assim, a autobiografia deve ser uma narrativa em prosa, retrospectiva, cujo assunto é a vida individual do autor e deve conter uma relação de identidade entre o autor, o narrador e o personagem. Percebemos, nos estudos de Lejeune (2007), uma preocupação eminente em diferenciar biografia e autobiografia. O autor caracteriza a autobiografia como um gênero que oscila entre a realidade e a ficção, de modo que o importante na autobiografia não seria a constatação do real, mas sim a semelhança com a realidade. Segundo o autor, os gêneros vizinhos da autobiografia, como

\footnotetext{
${ }^{4}$ Diferentemente do que ocorre na Argentina e no Chile, no Brasil poucas produções literárias são conhecidas quando o tema é a memória histórica sobre a ditadura. Talvez este silêncio explique os protestos acontecidos ao longo do ano de 2015 nas principais capitais do país, sobretudo em São Paulo, com faixas e cartazes que pedem abertamente a volta do regime militar, como uma evidência do esquecimento e da falta de memória histórica e literária do sangue derramado por inúmeros brasileiros na ditadura.
} 
memória, biografia, romance pessoal, diário, poema autobiográfico e autorretrato não preencheriam todas as condições indicadas nas categorias citadas e, desta forma, Lejeune resolve o problema da definição do gênero a partir da noção, hoje célebre, de "pacto autobiográfico":

Voltemos ao aspecto jurídico: uma das críticas feitas à noção de pacto é que ela supõe a reciprocidade, um ato em que duas partes se comprometem mutuamente a fazer alguma coisa. Ora, no pacto autobiográfico, como, aliás, em qualquer "contrato de leitura", há uma simples proposta que só envolve o autor: o leitor fica livre para ler ou não e, sobretudo, para ler como quiser. Isso é verdade. Mas se decidir ler, deverá levar em conta essa proposta, mesmo que seja para negligenciá-la ou contestá-la, pois entrou em um campo magnético cujas linhas de força vão orientar sua reação. Quando você lê uma autobiografia, não se deixa simplesmente levar pelo texto como no caso de um contrato de ficção ou de uma leitura simplesmente documentária, você se envolve no processo: alguém pede para ser amado, para ser julgado, e é você quem deverá fazê-lo. (LEJEUNE, 2007, p. 73).

Acreditamos que a teoria do pacto autobiográfico apresentado por Lejeune (2008) é falha, pois a autobiografia de Gabriel García Márquez transcende a ideia do contrato de leitura firmado entre leitor e escritor. A noção de pacto apresenta uma insuficiência teórica que se relaciona ao fato de que a autobiografia está permeada de elementos ficcionais. Esses elementos, dos quais trataremos mais adiante, colocam a obra de García Márquez em um lugar ambíguo, talvez mais próximo daquilo que a crítica contemporânea tem chamado de autoficção, sem, no entanto encontrar nesta classificação uma acolhida totalmente confortável.

Acreditamos que as mesmas categorias empregadas por Lejeune para definir autobiografia (forma da linguagem, assunto tratado, situação do autor e posição do narrador) poderiam ser encontradas na autoficção. Só restaria, portanto, a noção de pacto autobiográfico como elemento diferenciador entre os dois gêneros.

O termo autoficção se estabelece nas discussões entre teóricos franceses, como o próprio Phillipe Lejeune e Serge Doubrovsky, o qual o teria cunhado para referir-se a seu romance Fils, na década de 1970 (NORONHA, 2014). O terreno da autoficção é instável, não é dos mais concretos, mas é dos mais desafiadores. Encarar a autoficção envolve aceitar o convite do escritor para caminhar entre as fronteiras tênues entre a realidade e o ficcional. Neste horizonte de perspectivas, sinalizamos para o processo autoficcional na construção da narrativa de Gabriel García Márquez, pois sua autobiografia mescla realidade e ficção, impossibilitando a delimitação destas fronteiras para o leitor e para o 
escritor. Certamente, os estudos contemporâneos não se ocupam de um olhar julgador da autobiografia como um gênero da realidade ou da ficção; essa discussão é irrelevante. O que interessa é perceber como a realidade e a ficção contribuem com uma escrita autoficional na autobiografia analisada.

Mas como conceituar a autoficção? Ou, como questionaria Jovita Noronha, “entre nós, autoficção seria o nome de quê?” (2014, p.19). Sabe-se que a autobiografia "clássica" se aproxima da autoficção, embora o compromisso destas categorias literárias seja diferente. O compromisso da autobiografia é narrar a realidade. No entanto, a narração é o produto infiel da memória que cotidianamente se dilui.

Em oposição a todas as formas de ficção, a biografia e a autobiografia são textos referenciais: exatamente como o discurso científico ou histórico, eles se propõem a fornecer informações a respeito de uma

"realidade" externa ao texto e a se submeter, portanto a prova de verificação. Seu objetivo não é a simples verossimilhança, mas a semelhança com o verdadeiro. (LEJEUNE, 2008, p. 36)

Algo há de ficcionalização nessa recuperação dos acontecimentos passados. Já a autoficção faz justamente dessa fronteira incerta entre realidade e ficção o seu centro. Gasparini parece entender a autoficção como um rótulo que insere a autobiografia no contexto contemporâneo:

Em minha opinião, o termo autoficção deveria ser reservado aos textos que desenvolvem, em pleno conhecimento de causa, a tendência natural a se ficcionalizar, própria à narrativa de si. Uma situação, uma relação, um episódio, são narrados e roteirizados, intensificados e dramatizados por técnicas narrativas que favorecem a identificação do leitor com o autor-herói-narrador. De um ponto de vista pragmático, são romances autobiográficos, baseados em um duplo contrato de leitura. No entanto, a partir do momento em que são designados pelo neologismo um pouco mágico de "autoficção", eles se tornam outra coisa. Não são mais textos isolados, esparsos, inclassificáveis, nos quais um escritor dissimula com mais ou menos engenho suas confidências sob um verniz romanesco, ou vice-versa. Inscrevem-se em um movimento literário e cultural que reflete a sociedade de hoje e evolui com ela. (...) Como disse Vicente Colonna no colóquio de Cerisy, "autoficção" é uma palavra-narrativa, que basta desdobrar para que apareçam todos os tipos de histórias pessoais. A sedução do termo se deve à sua ambiguidade, a seu mistério. Todos podem se apropriar dele ou rejeitá-lo em função de sua própria identidade narrativa e de sua própria mitologia estética. Palavrateste, palavra-espelho, que nos devolve as definições que lhe atribuímos. (GASPARINI, 2014, p. 217-218). 
Ao instalar-se na ambiguidade, a noção de autoficção coloca em cheque a estabilidade do conceito de autobiografia. Nota-se em Alberca (2006) o desafio da autoficção como uma categoria que pretende romper o pacto de leitura proposto por Lejeune (2007), estabelecendo, nos textos autoficcionais, a possibilidade de caminhar entre o autobiográfico e o ficcional.

En resumen, la autoficción pretende romper los esquemas receptivos del lector (o al menos hacerle vacilar), al proponerle un tipo de lectura ambigua: si por una parte parece anunciarle un pacto novelesco, por otra, la identidad del autor, narrador y personaje le sugiere una lectura autobiográfica. De acuerdo con este planteamiento, la autoficción y sus posibles variantes tipológicas, tiene algo de antipacto o contrapacto autobiográfico, que en un sentido emborrona la explicativa teoría del "pacto autobiográfico" de Philippe Lejeune y al mismo tiempo la pone a prueba o a la completa. Pero sobre todo, y esto es para mí lo más importante por controvertido que pueda ser desde la poética del relato, permite precisar el gradualismo variable y complejo con que el lector tiene que descifrar en estos textos situados a caballo de los dos grandes pactos narrativos, el autobiográfico y el ficticio. (ALBERCA, 2006, p. 09).

Assim, percebe-se a autoficção como resultado de uma prática de escrita hibrida que envolve o discurso autobiográfico - que deve ter compromisso com a verossimilhança - e a ficção - no qual não há, necessariamente, um compromisso com a realidade.

\section{4- Vivir para contarla: as memórias de Gabriel García Márquez}

No que se refere à obra literária de Gabriel García Márquez, poucos estudos têm se ocupado da autobiografia Vivir para contarla sob a ótica das escritas de si. Não obstante, na teoria e crítica literária, a autobiografia em questão é considerada um clássico quando o tema é as memórias do escritor García Márquez.

O livro trata de momentos importantes da trajetória do escritor e do contexto literário e histórico colombiano. Além de contar eventos da sua vida quando criança, adolescente e adulto, como o dia em que sua mãe lhe pediu que o acompanhasse para vender a casa em Aracataca e a Matança Pública ocorrida na Colômbia, o escritor também narra o período em que ele se reconheceu como escritor, momentos de produção de outras obras importantes e suas participações no El Heraldo. A obra conta com sete capítulos que relatam os principais acontecimentos da vida do escritor. No primeiro capítulo o 
colombiano conta suas recordações na cidade de Aracataca, onde tudo começou. O segundo capítulo mostra o processo de Gabriel García Márquez de se reconhecer como escritor, indo contra o desejo da família. O capítulo seguinte se dedica às guerras civis na Colômbia, assim como ao desastre que matou seu avô. O quarto e quinto capítulos mostram a vida do escritor nas principais cidades caribenhas, destacando o período em que García Márquez recebe a escolarização formal. O sexto capítulo trata da importância da cidade de Cartagena de Índias em sua formação cultural. O último capítulo narra a vida de reconhecimento do escritor ao redor do mundo e o sucesso de sua obra.

O livro se apresenta como uma autobiografia e se supõe que os eventos e personagens ali mencionados de fato existiram. Como em toda autobiografia, a de García Márquez se apoia em uma quantidade de elementos que reforçam a relação de identidade entre o texto e os acontecimentos reais, como a foto do escritor quando criança e sua assinatura na capa.

No entanto, na epígrafe de abertura da autobiografia, Gabriel García Márquez se desculpa ao leitor pela impossibilidade de atestar que a narrativa é fiel aos fatos, tendo em vista a impossibilidade de confiar na memória: "la vida no es la que uno vivió, sino la que uno recuerda y cómo la recuerda para contarla" (GARCÍA MÁRQUEZ, 2007 , p. 08). Algo similar ocorre na contracapa, quando Carlos Fuentes (2007) diz: "A los que un día dirán: "Esto fuiste”, "Esto hiciste" o "Esto imaginaste”, Gabo se les adelanta y dice simplemente: soy, seré, imaginé. Esto recuerdo. Gracias por la memoria." Assim, as falas de García Márquez e de Fuentes parecem defender preventivamente o escritor da hipotética acusação de estar fazendo ficção quando deveria ater-se à realidade.

Em alguns trechos da narrativa, Gabriel García Márquez utiliza a expressão lembranças falsas para construir episódios e momentos de sua vida, como nos trechos abaixo:

Hasta muy poco antes de su muerte le oí contar que uno de aquellos días difíciles tuvo que ir con varios amigos a la casa del coronel, y a todos los invitaron a sentarse, menos a él. La familia de ella lo negó siempre y se lo atribuyó a un rescoldo del resentimiento de mi padre, o al menos a un falso recuerdo, pero a mi abuela se le escapó alguna vez en los desvaríos cantados de sus casi cien años, que no parecían evocados sino vueltos a vivir. (GARCÍA MÁRQUEZ, 2007, p. 62)

Mi madre añoraba tanto la casa donde pasó la luna de miel, que sus hijos mayores hubiéramos podido describirla cuarto por cuarto como si la hubiéramos vivido y todavía sigue siendo uno de mis falsos recuerdos. Sin embargo, la primera vez que fui en realidad a la península de $\mathrm{La}$ 
Guajira, poco antes de mis sesenta años, me sorprendió que la casa de la telegrafía no tenía nada que ver con la del recuerdo. Y la Riohacha idílica que llevaba desde niño en el corazón, con sus calles de salitre que bajaban hacia un mar de lodo, no era más que ensueños prestados por mis abuelos. Más aún: ahora que conozco Riohacha no consigo visualizarla como es, sino como la había construido piedra por piedra en mi imaginación. (GARCÍA MÁRQUEZ, 2007. p. 70).

Desta forma, percebemos que a autobiografia em questão apresenta características das autobiografias "clássicas", que têm o compromisso de narrar a realidade e de se aproximar da verossimilhança o máximo possível. Contudo, percebe-se que, apesar destas características, Vivir para Contarla também parece reivindicar a possibilidade de ser lida como ficção. Se existe, aqui, algum tipo de pacto entre autor e leitor, este é um pacto que, em lugar de comprometer o autor e designar-lhe uma responsabilidade, libera-o do compromisso e garante a ele a liberdade para transitar entre o real e o ficcional, justificando, a partir da fiabilidade da memória, qualquer desvio da verdade.

\section{5- O artifício da memória e as fronteiras entre a realidade e a ficção}

Na construção dos gêneros de memória, sobretudo no caso da autobiografia, é importante considerar que a escrita tem uma função indireta de imortalizar o escritor. Talvez uma ânsia de permanência justifique a necessidade do escritor de contar os fatos relevantes da sua vida. Assim, a função da memória seria a de imortalizar:

Não é apenas o de simples reconhecimento de conteúdos passados, mas um efetivo reviver que leva em si todo ou parte deste passado. É o de fazer aparecer novamente as coisas depois que desaparecem. É graças à faculdade de recordar que, de algum modo, escapamos da morte que aqui, mais que uma realidade física, deve ser entendida como a realidade simbólica que cria o antagonismo-chave com relação ao nosso tema: o esquecimento. $\mathrm{O}$ esquecimento é a impermanência, a mortalidade. (ROSÁRIO, 2002 apud BEZERRA (2011, p. 21)).

Como antídoto para a mortalidade, no entanto, a autobiografia oferece a reconstrução imperfeita de uma realidade que já não é apreensível nem verificável. Ela não elimina o esquecimento, apenas substitui as lacunas por ele deixadas. Além disso, o escritor de autobiografia projeta os acontecimentos a partir de sua subjetividade e pode 
dar ênfase a eventos considerados irrelevantes para outros, bem como esconder aspectos da história que não lhe interessa revelar.

A autobiografia conta com o artifício da memória como suporte para a reconstituição das histórias narradas, mas até que ponto a memória é fiel aos fatos? Somos capazes de narrar com fidelidade eventos acontecidos quando éramos crianças? A negação parece ser evidente. Em certo momento do texto, García Márquez reforça essa conclusão ao falar de sua capacidade da fabulação na infância e do modo como ele, quando menino, se apropria da realidade e a transforma a seu gosto:

Quienes me conocieron a los cuatro años dicen que era pálido y ensimismado, y que sólo hablaba para contar disparates, pero mis relatos eran en gran parte episodios simples de la vida diaria, que yo hacía más atractivos con detalles fantásticos para que los adultos me hicieran caso. Mi mejor fuente de inspiración eran las conversaciones que los adultos sostenían delante de mí, porque pensaban que no las entendía, o las que cifraban aposta para que no las entendiera. Y era todo lo contrario: yo las absorbía como una esponja, las desmontaba en piezas, las trastocaba para escamotear el origen, y cuando se las contaba a los mismos que las habían contado se quedaban perplejos por las coincidencias entre lo que yo decía y lo que ellos pensaban. (GARCÍA MÁRQUEZ, 2007, p. 94).

Mas é, talvez, no fragmento abaixo, que o autor deixa mais clara a compreensão da memória como ficcionalização da realidade:

Tantas versiones encontradas han sido la causa de mis recuerdos falsos. Entre ellos, el más persistente es el de mí mismo en la puerta de la casa con un casco prusiano y una escopetita de juguete, viendo desfilar bajo los almendros el batallón de cachacos sudorosos. Uno de los oficiales que los comandaba en uniforme de parada me saludó al pasar: - Adiós, Capitán Gabo.

El recuerdo es nítido, pero no hay ninguna posibilidad de que sea cierto. El uniforme, el casco y la escopeta coexistieron, pero dos años después de la huelga y cuando ya no había tropas de guerra en Cataca. (GARCÍA MÁRQUEZ, 2007, p. 73).

A memória trai o indivíduo com o esquecimento. A lembrança pode se apagar, se desconstruir e o que sobra é uma reconstrução imperfeita. Mas o escritor também se apoia nas fontes históricas, na memória coletiva e nos relatos de terceiros, que assume, muitas vezes, como seus: "Fue allí, según me precisó mi madre aquel día, donde el ejército había 
matado en 1928 un número nunca establecido de jornaleros del banano. Yo conocía el episodio como si lo hubiera vivido y mil veces repetido por mi abuelo desde que tuve memoria" (GARCIA MÁRQUEZ, 2007, p. 21). Entretanto, ao tentar recompor os fatos a partir dessas fontes, o autor enfrenta o desencontro das informações e os efeitos da supressão da memória coletiva operada por mecanismos do poder. É o que ocorre em seu intento de reconstituir o episódio conhecido como la masacre de las bananeras, ocorrido em 1928, quando o exército colombiano reprimiu com um genocídio uma greve de trabalhadores da empresa United Fruit Company (que mais tarde mudaria seu nome para Chiquita Brands) ${ }^{5}$. Nunca foi possível estabelecer o número de mortos e o silêncio imposto à população fez proliferar uma quantidade enorme de relatos díspares, sem que seja possível determinar qual deles mais se aproximaria da realidade:

El origen de todas las desgracias, por supuesto, había sido la matanza de los obreros por la fuerza pública, pero aun persistían las dudas sobre la verdad histórica: tres muertos o tres mil? Quizás no habían sido tantos, dijo él, pero cada quien aumentaba la cifra de acuerdo con su propio dolor. (GARCÍA MÁRQUEZ, 2007, p. 36)

Es una sentencia fiel al estilo liberal de la época pero no he podido conciliarla con el talante del abuelo. La verdad es que no hubo testigos. Una versión autorizada habrían sido los testimonios judiciales del abuelo y sus contemporáneos de ambos bandos, pero del expediente, si lo hubo, no quedaron ni sus luces. De las numerosas versiones que escuché hasta hoy no encontré dos que coincidieran. (GARCÍA MÁRQUEZ, 2007, p. 49)

Solo así se explica el horror de "La noche negra de Aracataca", una degollina legendaria con un rastro tan incierto en la memoria popular que no hay evidencia cierta de si en realidad sucedió. (GARCÍA MÁRQUEZ, 2007, p. 51)

Mi madre no me entendió. Más aún: cuando pasamos frente a la Casa de María Consuegra no miró siquiera la puerta donde todavía se notaba el remiendo de la madera en el boquete del balazo. Años después, rememorando con ella aquel viaje, comprobé que se acordaba de la tragedia, pero había dado el alma por olvidarla. (GARCÍA MÁRQUEZ, 2007, p. 32)

\footnotetext{
5 Foi uma multinacional americana que se destacou na produção e venda de frutas na América Latina, sobretudo na Colômbia. Ficou conhecida como a "República das Bananas", dado o poder da empresa nos países do terceiro mundo e seu envolvimento com os Estados Unidos. Sua atuação foi marcada por inúmeras irregularidades, e na Colômbia, especialmente, pelo massacre aos trabalhadores.
} 
O fato de este mesmo incidente histórico ter sido ficcionalizado por García Márquez, transformando-se em um dos momentos-chave do romance Cien años de soledad (1967), reforça o vínculo entre a autobiografia e a obra ficcional do autor, levando-nos a pensar que essa relação fluída e ambígua entre realidade e ficção não se dá exclusivamente na autobiografia, mas é parte constitutiva de seu próprio projeto estético. Basta lembrar que o realismo maravilhoso, do qual García Márquez se tornou o representante mais célebre, se apoia na ideia de que, na América Latina, a própria realidade - seja pela opulência da natureza, seja pelo absurdo dos acontecimentos históricos ou pela mistura de crenças e superstições - é essencialmente mágica. Alejo Carpentier conclui seu conhecido prólogo a El reino de este mundo (1948) com a pergunta retórica: "Pero qué es la historia de América toda sino una crónica de lo real maravilloso?"

(CARPENTIER, 2005, p.16) E o próprio García Márquez insiste na maravilha cotidiana como elemento singular da realidade latino-americana em seu discurso de aceitação do prêmio Nobel, em 1982:

Una realidad que no es la del papel, sino que vive con nosotros y determina cada instante de nuestras incontables muertes cotidianas, y que sustenta un manantial de creación insaciable, pleno de desdicha y de belleza, del cual éste colombiano errante y nostálgico no es más que una cifra más señalada por la suerte. Poetas y mendigos, músicos y profetas, guerreros y malandrines, todas las criaturas de aquella realidad desaforada hemos tenido que pedirle muy poco a la imaginación, porque el desafío mayor para nosotros ha sido la insuficiencia de los recursos convencionales para hacer creíble nuestra vida. Este es, amigos, el nudo de nuestra soledad. ${ }^{6}$

Assim, a mesma busca de um modo adequado para representar uma realidade inapreensível pelos códigos da racionalidade, que caracteriza toda a obra ficcional de García Márquez, volta a atravessar seu texto quando ele, já no fim da vida, adota um gênero referencial como a autobiografia. Esse encontro entre ficção e relato do verídico e essa visão da maravilha como constitutiva da realidade cotidiana são tão presentes na autobiografia que muitos trechos de Vivir para contarla poderiam perfeitamente figurar em um de seus romances, como se vê abaixo:

\footnotetext{
${ }^{6}$ Discurso de Gabriel García Márquez na cerimônia do Prêmio Nobel de Literatura: " $L a$ soledad de América Latina". In: Ciudad Seva (ver bibliografia final).
} 
A veces no sabía qué hacer con mi consciencia y trataba de disimularlo con parpadeos rápidos. Tanto era así, que algún racionalista de la familia decidió que me viera un médico de la vista, el cual atribuyó mis parpadeos a una afección de las amígdalas, y me recetó un jarabe de rábano yodado que me vino muy bien para aliviar a los adultos. La abuela, por su parte, llegó a la conclusión providencial de que el nieto era adivino. Eso la convirtió en mi víctima favorita, hasta el día en que sufrió un vahído porque soné de veras que al abuelo le había salido un pájaro vivo por la boca. El susto de que se muriera por culpa mía fue el primer elemento de mi desenfreno precoz. Ahora pienso que no eran infamias de niño, como podía pensarse, sino técnicas rudimentarias de narrador en ciernes para hacer la realidad más divertida y comprensible. (GARCÍA MÁRQUEZ, 2007, p. 95)

É nesta perspectiva do jogo com a realidade e a ficção que a obra de Gabriel García Márquez se encontra, desafiando os limites da escrita autobiográfica e ancorando-se numa escrita autoficional que brinca com os limites da autobiografia.

\section{Considerações finais}

Vivir para contarla encontra-se nas fronteiras entre a realidade e a ficção. O leitor não pode delimitar estas fronteiras, pois o autor próprio autor se exime de defini-las. Assim, por um lado, Vivir para contarla se insere no conjunto de textos considerados como autobiográficos, pois a priori o narrador conta a sua história de vida, de modo retrospectivo, com todas as características de uma autobiografia "tradicional". Por outro lado, no entanto, esta obra torna problemática a noção lejeuneana de pacto autobiográfico. O pacto que García Márquez estabelece com o leitor não é o de aceitação do texto como verdade, mas, ao contrário, o da aceitação da impossibilidade de fixar a verdade.

Assim, podemos pensar que Vivir para Contarla se aproxima da autoficção. Entretanto, encontrar um outro rótulo para a obra que não se relacione à autoficção seria ignorar a dimensão do problema que García Márquez nos coloca. Ao inserir no texto o elemento da incerteza - uma marca da contemporaneidade - García Márquez nos obriga a repensar as convenções de gênero e as ferramentas de leitura que tradicionalmente serviram para singularizar a autobiografia. Embora não esteja preocupado com essas definições, o que o autor faz é colocar em questão o próprio estatuto da autobiografia como um gênero referencial. Não existe uma relação de identidade entre o texto e a realidade. A única relação possível é entre texto e memória. E se a memória é, ela mesma, 
uma representação e uma reconstrução sempre imperfeita do real, tudo o que autobiografia pode nos oferecer é uma representação de segunda mão.

\section{REFERÊNCIAS BIBLIOGRÁFICAS}

ALBERCA, Manuel. Existe la autoficción hispano-americana? Cuadernos del Cilha, 2005. http://bdigital.uncu.edu.ar/objetos digitales/1095/albercacilha78.pdf Consultado em 23 de agosto de 2015.

ARFUCH, Leonor. O espaço biográfico: dilemas da subjetividade contemporânea. Rio de Janeiro: EdUERJ, 2010.

BEZERRA, Luciana da Silva. A escrita intinerante de Maria Ondina Braga. Autobiografia, ficção e memória. Tese de Doutorado em Língua Portuguesa Faculdade de Letras - Universidade Federal do Rio de Janeiro, 2011.

CARPENTIER, Alejo. "Prólogo". In: El reino de este mundo. Caracas: Fundación Celarg, 2005.

COMPAGNON, Antoine. Literatura para quê? Belo Horizonte: UFMG, 2009.

COSTA JUNIOR, José Veranildo Lopes da. Vivir para Contarla: escritura del yo y memoria en Gabriel García Márquez. Trabalho de Conclusão de Curso - Universidade Estadual da Paraíba, 2014.

CRAVINO, Graciela. Gabriel García Márquez: Mucho más que macondo. Buenos Aires, Capital Intelectual, 2008.

FOUCAULT, Michael. A escrita de si. In: O que é um autor? Lisboa: Passagens, 1992.

GARCIA MÁRQUEZ, Gabriel. Vivir para contarla. 5a ed.- Buenos Aires: Debolsillo, 2007.

. "La soledad de América Latina". In: Ciudad Seva. Disponível em: http://www.ciudadseva.com/textos/otros/la_soledad_de_america_latina.htm. Consultado em: 24 de agosto de 2015.

GASPARINI, Phillippe. Autoficção é o nome de quê? In: Ensaios sobre a autoficção. Belo Horizonte: Editora UFMG, 2014.

KLINGER, Diana. Escritas de si, escritas do outro: o retorno do autor e a virada etnográfica. Rio de Janeiro: 7Letras, 2007. 
LEJEUNE, Philippe. O pacto autobiográfico: de Rousseau à Internet. Belo Horizonte: Editora UFMG, 2008.

LEITE, Graziela O. Amor e erotismo. Realidade e ficção: a diversidade em memória de mis putas tristes de Gabriel García Márquez. Universidade Federal do Rio de Janeiro Programa de Pós-Graduação em Letras Neolatinas, 2011.

LIMA, Luiz Costa. História. Ficção. Literatura. São Paulo: Companhia das Letras, 2006.

MENDONZA, Plinio Apuleyo. Un García Márquez desconocido (Aquellos tiempos con Gabo). Bogotá: Emecé Editores, 2009.

NORONHA, Jovita Maria Gerheim. Ensaios sobre a autoficção. Belo Horizonte: Editora UFMG, 2014.

PESSOA, Marcelo. Cem anos de solidão e Viver para Contar, de Gabriel Garcia Márquez: expressões de identidade sociocultural latino-americana. In: Congresso Internacional da ABRALIC. Curitiba, 2011.

SALDÍVAR, Dasso. García Márquez: el viaje a la semilla. Ediciones Folio S.A, 2005.

TODOROV, Tzvetan. Descubrir. In: La conquista de América: el problema del otro. Buenos Aires: Siglo Veintiuno Editores, 2011. 